\title{
Humming in Tune: Sex and Species Recognition by Mosquitoes on the Wing
}

\author{
Gabriella Gibson $^{1,2}$, Ben Warren ${ }^{1}$, and Ian J. Russell ${ }^{1}$ \\ ${ }^{1}$ School of Life Sciences, University of Sussex, Falmer, Brighton, BN1 9QG, UK \\ ${ }^{2}$ Natural Resources Institute, University of Greenwich at Medway, Chatham Maritime, Kent, ME4 4TB, UK
}

Received: 10 September 2010; Accepted: 17 October 2010; Online publication: 26 October 2010

\begin{abstract}
Mosquitoes are more sensitive to sound than any other insect due to the remarkable properties of their antennae and Johnston's organ at the base of each antenna. Male mosquitoes detect and locate female mosquitoes by hearing the female's flight tone, but until recently we had no idea that females also respond to male flight tones. Our investigation of a novel mechanism of sex recognition in Toxorhynchites brevipalpis revealed that male and female mosquitoes actively respond to the flight tones of other flying mosquitoes by altering their own wing-beat frequencies. Male-female pairs converge on a shared harmonic of their respective fundamental flight tones, whereas same sex pairs diverge. Most frequency matching occurs at frequencies beyond the detection range of the Johnston's organ but within the range of mechanical responsiveness of the antennae. We have shown that this is possible because the Johnston's organ is tuned to, and able to detect difference tones in, the harmonics of antennal vibrations which are generated by the combined input of flight tones from both mosquitoes. Acoustic distortion in hearing organs exists usually as an interesting epiphenomenon. Mosquitoes, however, appear to use it as a sensory cue that enables malefemale pairs to communicate through a signal that depends on auditory interactions between them. Frequency matching may also provide a means of species recognition. Morphologically identical but reproductively isolated molecular forms of Anopheles gambiae fly in the same mating swarms, but rarely
\end{abstract}

Correspondence to: Ian J. Russell · School of Life Sciences · University of Sussex·Falmer, Brighton, BN1 9QG, UK. email: i.j.russell@ sussex.ac.uk hybridize. Extended frequency matching occurs almost exclusively between males and females of the same molecular form, suggesting that this behavior is associated with observed assortative mating.

Keywords: mosquito, hearing, frequency tuning, distortion products, difference tones, frequency matching, sexual recognition, species recognition, Johnston's organ

\section{INTRODUCTION}

Anopheles gambiae s.l. has been described as the most dangerous animal in the world, responsible for the majority of malaria deaths worldwide, killing 1-2 million people annually and ranked the second highest contributor to the global Disability Adjusted Life Year in Africa (WHO 2002). If we take into account the populations of all species of mosquito that transmit pathogens and parasites to humans and their domestic livestock worldwide, mosquitoes easily cause more human suffering than any other organism. Their sensory physiology is finely tuned to locate host animals mainly by olfactory cues, and their visual system is well adapted to locating hosts mainly in the dark at times of day when hosts are most quiescent and least able to defend themselves from bites, making them one of the few insects that routinely fly at night (Gibson and Torr 1999; Land et al. 1999). It is beginning to become apparent that their auditory system is one of the most highly developed among the insects.

The males of most mosquito species of medical importance are known to locate mates by sound; 
males aggregate over conspicuous markers and fly continuously in swarming flight, keeping station over the marker. Virgin females are also attracted to the same markers, which are generally, but not universally species-specific. When a male detects the flight tone of a female, he chases her by localizing the source of her flight tone. This mating chase normally leads to the formation of a mating copula. The mechanisms by which male mosquitoes detect and locate females has been reasonably well understood for many years (Charlwood and Jones 1979; Belton 1994; Clements 1999). It has been proposed that the male auditory organ acts as an acoustic filter for female flight tones, but the evidence so far suggests that the filter is too broad and flight tone frequencies alone are not sufficiently species-specific to be the basis for male identification of conspecies females (Tripet et al. 2001). Audition is, therefore very important to mosquitoes for sexual and perhaps species recognition.

In recent years, interest in the mating behavior of mosquitoes has increased for two key reasons; (1) to understand the basis of complex patterns of reproductive isolation in sympatric populations of closely related molecular forms of the malaria mosquito $A$. gambiae s.s. that do not hybridize even though they occur in the same mating swarms (della Torre et al. 2002), and (2) to investigate the likely efficacy of using genetically modified mosquitoes to control wild populations. The approach is only possible if we can ensure that laboratory reared populations will respond appropriately to the mating behavior of wild mosquitoes. Hence, we have undertaken an extended investigation of the auditory behavior of mosquitoes in relation to mating interactions.

\section{Mosquito Audition}

Mosquitoes hear with their antennae (Fig. 1A), each of which consists of an elongate flagellum and a chordotonal organ housed within the pedicel at the base of each antenna called the Johnston's organ (JO) after the man who discovered it $>150$ years ago (Fig. 1B, Belton 1989). The flagellum vibrates when stimulated by periodic air displacements (the acoustic near-field) such as the tones created by wing beats (Göpfert and Robert 2000). At its base, the flagellum tapers into a structure of 60-80 prongs (Fig. 1B), which resemble the spokes of an upturned umbrella. The prongs are attached to many thousands of mechanosensory sensillae known as the scolopidia of the JO (Fig. 1A and B). It is not known precisely how these mechanosensory cells are stimulated, but it is likely they detect the rocking action of the prongs when the flagellum is vibrated through displacement of air particles.
In many mosquito species, the antennae are sexually dimorphic, with males having a greater number of sensillae in the JO $(\sim 14,000$ in males, $\sim 7,000$ in females, Göpfert et al. 1999) and a greater number of fibrillae (fine hair-like structures) on the flagellum (Fig. 1A), which led Johnston to speculate that for these mosquitoes, mating behavior involved audition (Johnston 1855). It is likely that the greater surface area of the male flagellum increases their responsiveness to particle displacement.

The sensillae mechanoelectrically transduce and amplify the nanometer sound-induced vibrations of the antennal flagellum into electrical signals (Göpfert and Robert 2000).

The sources of extracellular electrical compound potentials from the JO of mosquitoes are believed to be extracellular currents associated with the generation of receptor potentials and action potentials in the JO (Fig. 1C-E; Tischner 1953; Keppler 1958; Wishart et al. 1962; Warren et al. 2009). As with recordings of the cochlear microphonic from the round window of the mammalian cochlea (Patuzzi et al. 1989), these potentials are overwhelmingly dominated by the receptor currents from the sensory cells closest to the extracellular electrode. Acoustically elicited receptor potentials recorded from the JO are composed of a tonic (DC) component, a phasic F1 component, and an F2 component that is twice the frequency of the applied acoustic stimulus (Fig. 1C and $\mathrm{D}$ ). The bandwidth of the F2 component has been used to determine the frequency limits of hearing in mosquitoes because it dominates the electrical response of the JO (Tischner 1953; Keppler 1958; Wishart et al. 1962; Belton 1974; Warren et al. 2009). The frequency doubling of the F2 component is thought to be due to the summed outputs of the nonlinear electrical responses of two populations of sensory cells in the scolopidia with opposite polarities of morphological and functional symmetry (Tischner 1953; Wishart et al. 1962; Belton 1974; Clements 1999; Warren et al. 2009), as has also been proposed for the frequency doubling of the microphonic potential of the lateral line receptors of fishes (Flock 1965). The phasic F1 component of the receptor potential dominates at high frequencies and low sound intensities, probably because potentials from only the scolopidial population nearest the electrode are recorded. Potentials from populations of scolopidia further away from the recording site, that are of opposite polarity and which would summate to produce a potential with twice the frequency of the stimulating frequency, are attenuated before reaching the electrode. A tonic component or direct current (DC) shift of the potential occurs upon and during presentation of a tone (Fig. 1C) but its precise origin has yet to be determined (Cator et al. 2009). 
A

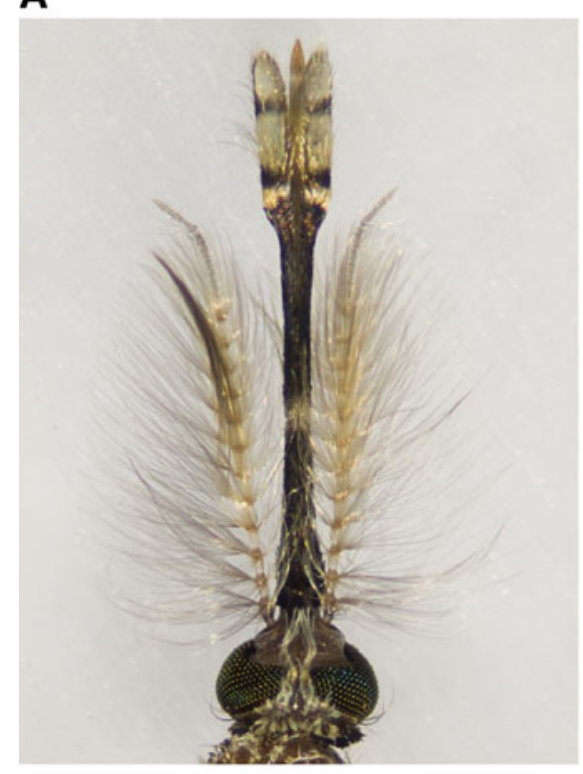

B

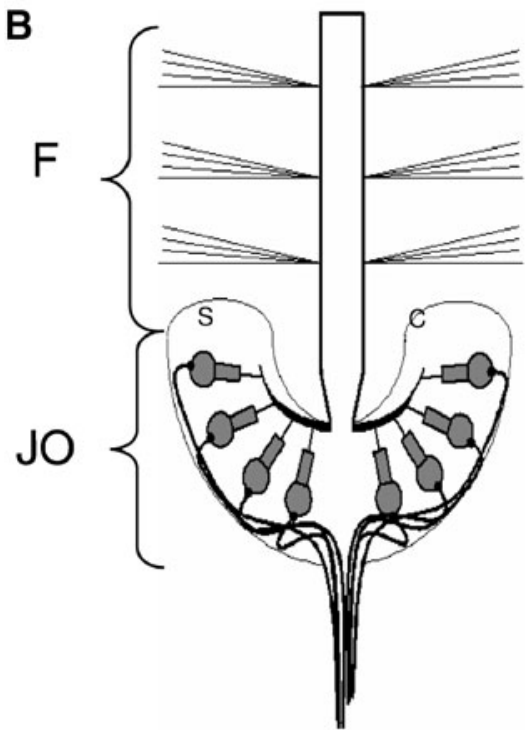

C

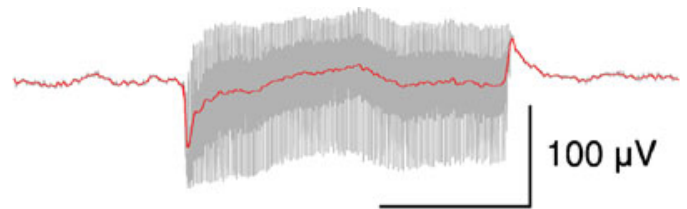

D

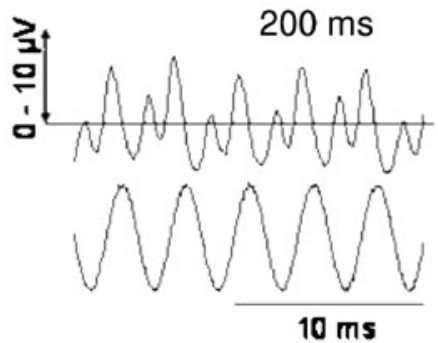

E

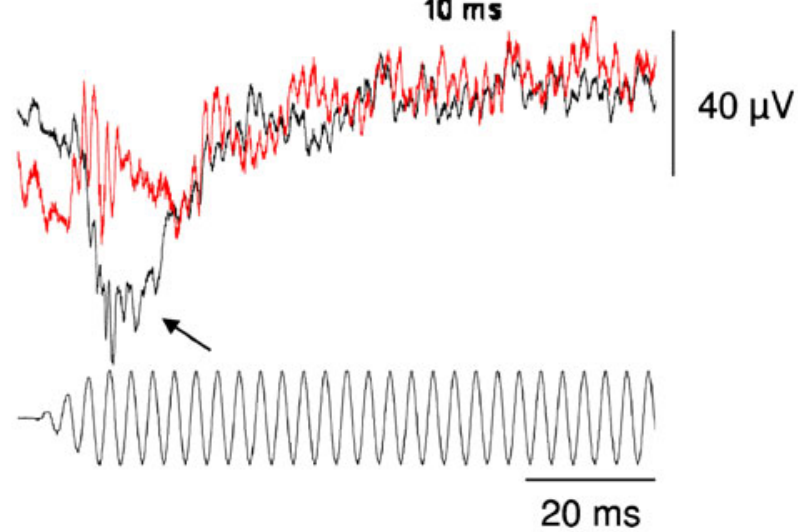

FIG. 1. Electrical potentials recorded from the Johnston's organ and thorax of mosquitoes. A Head and antennae of male A. gambiae mosquito with fibrillae extended. B Schematic diagram showing a cross-section of the antenna of a mosquito with the flagellum of the antenna $(F)$ inserted into the cup-shaped pedicel that houses the complex arrangement of cuticular processes $(C)$ and attached, mechanosensory scolopidia $(S)$ of the Johnston's organ $(J O$; Belton 1989). C Receptor potential (gray) with direct current (DC) component (red line) from a male $A$. gambiae with collapsed fibrillae in response to a $300 \mathrm{~Hz}$ tone, particle velocity $0.0011 \mathrm{~ms}^{-1}$. D Extracellular (double frequency) receptor potential recordings from the JO of a male Culex pipiens in response to a $300.3 \mathrm{~Hz}, 36 \mathrm{~dB} \mathrm{SPL}$, $0.00405 \mathrm{~ms}^{-1}$ tone (command voltage to speaker, lower trace;

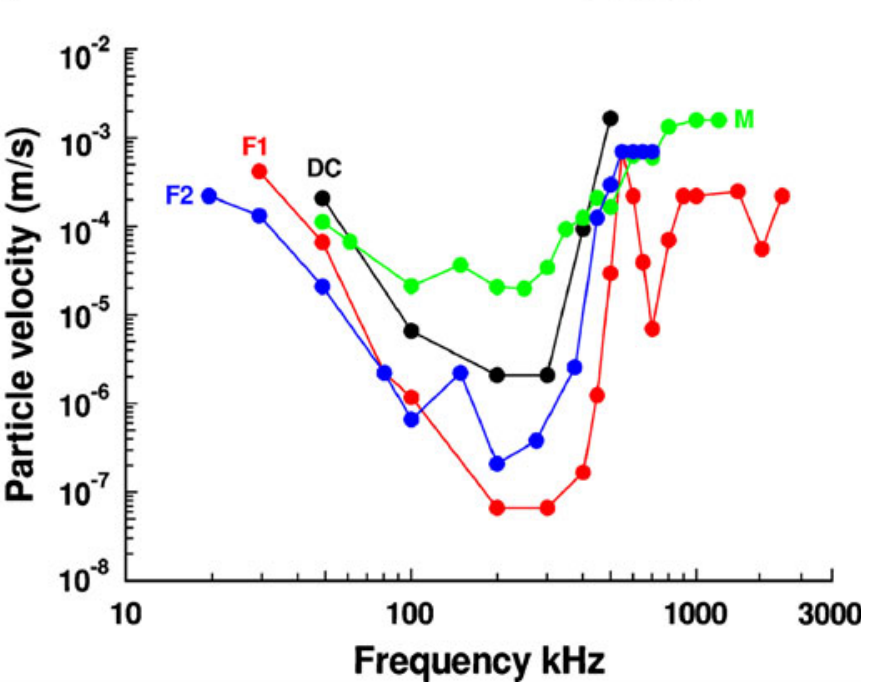

modified from Pennetier et al. 2010, with permission of the publisher). E Compound voltage responses (upper trace) recorded from the $\mathrm{JO}$ of male $\mathrm{M}$-form $A$. gambiae mosquito in response to a $300.3 \mathrm{~Hz}$ tone, particle velocity $0.56 \mathrm{mms}^{-1}$ (lower trace) before (black) and after (red) injecting $1 \mu \mathrm{M}$ tetrodotoxin (TTX, SigmaAldrich) in insect saline into the thorax. Note loss of onset (neural) potential, but not phasic (2f) component after TTX injection. F Threshold frequency tuning curves measured from of the F1, F2, and DC components of the extracellular receptor potential recorded from the $\mathrm{JO}$ of a male $C$. pipiens and neural motor $(\mathrm{M})$ responses recorded from the thorax (E and $\mathbf{F}$ modified from Warren et al. 2010, with permission of publisher (all Anopheles figures modified from Warren et al. 2009, with permission of publisher). 
Efforts to establish the upper frequency limit of hearing by mosquitoes have led to a wide range of differing results. Discrepancies in published findings may be due to the use of the different components of the extracellular potentials of the JO to assess the bandwidth of hearing in mosquitoes (Belton 1974; Clements 1999; Pennetier et al. 2010; Warren et al. 2009; Arthur et al. 2010), and to differences in the maximum particle velocity level used for acoustic stimulation, differences in location of the electrode in the JO and differences in criteria of the thresholds used to derive tuning curves. Our most recent approach was to construct a threshold behavioral audiogram from motor potentials ("M", Fig. 1F) recorded from the thorax (Warren et al. 2009), which we found to be less sensitive than those derived from the phasic and DC potentials recorded from the JO of the same mosquito, but its high-frequency limit corresponded to that set by the F1 phasic receptor potentials ("F1", Fig. 1F).

\section{FREQUENCY MATCHING AT FUNDAMENTAL WING-BEAT FREQUENCIES; TOXORHYNCHITES BREVIPALPIS}

Given the extraordinary acoustic sensitivity of both male and female mosquitoes and the wealth of evidence that male mosquitoes alter their flight behavior in response to the flight tone of another mosquito, we hypothesized that mosquitoes must have a means of detecting the external sounds of another mosquito flying nearby against the background sounds of their own wing beats. Might mosquitoes alter their own sound production (i.e., change their own wing-beat frequency) in response to external sound stimuli to find out more about the external sound? Hence, we first sought to explore the effects of an artificial controlled sound stimulus delivered via a calibrated speaker on the wing-beat behavior of a tethered-flying mosquito placed $\sim 3 \mathrm{~cm}$ away (Fig. 2A). We chose to work with $T$. brevipalpis Theobald, a relatively large (wingspan $\sim 2.5 \mathrm{~cm}$, compared to $<1 \mathrm{~cm}$ for the other species referred to here) and easy-to-handle species. Mosquito wing beats are complex with many vibration modes that generate flight tones with multiple harmonics (Fig. 2B and C), but our analysis of the data in this study was restricted to the fundamental frequency (arrow, Fig. 2C) since it is this component that falls within the most sensitive frequency range of the antenna and the auditory system of this species, as revealed by behavioral audiograms obtained for males and females (Fig. 3A, described below). Unlike most species, the wing-beat frequencies of male and female $T$. brevipalpis are similar. We found that, irrespective of the base-line wing-beat frequency of individual mosquitoes, both sexes responded to a pure-tone sound stimulus by altering their wing-beat frequencies to converge on the pure tone, and sustained this near-frequency matching for the duration of the stimulus tone if the pure tone was within $\sim 60 \mathrm{~Hz}$ of their base-line wingbeat frequency (i.e., $\sim 350-500 \mathrm{~Hz}$; Fig. 2D). If the tone was quite different in frequency to their wing beats (i.e., 200-345 and 500-800 Hz), however, they responded with a transient increase in wing-beat frequency (Fig. 2E).

\section{Behavioral Frequency Tuning Curves}

The frequency convergence and transient responses of the mosquitoes to pure tones enabled us, for the first time, to derive mosquito behavioral auditory tuning curves for each sex (Fig. 3A). A response was scored if the mosquito either altered its wing-beat frequency upward or downward in response to the stimulus tone frequency. The overall shape of the male and female behavioral auditory threshold curves (Fig. 3A) show that there is a relatively sharp transition in behavior and sensitivity of response at $\sim 350$ and $\sim 500 \mathrm{~Hz}$. At stimulus frequencies between $350-500 \mathrm{~Hz}$ (indicated by the blue region in Fig. 3A) mosquitoes converged on the stimulus tone, even when it was delivered at remarkably low $\mathrm{dB}$, whereas for stimulus frequencies outside this range (200-345 and 500-800 $\mathrm{Hz}$ ), mosquitoes responded with a transient change in their wing-beat frequencies, but only if the stimulus was delivered at a relatively high $\mathrm{dB}$. Mosquitoes appeared to be unable to converge on stimulus tones outside the $400-500 \mathrm{~Hz}$ range.

The behavioral tuning curves of males and females are similar in shape, most sensitive at frequencies close to $400 \mathrm{~Hz}$, and show males to be approximately seven times more sensitive than females, responding to tone levels which displace their antennae by $0.8 \mathrm{~nm}$ at $400 \mathrm{~Hz}$ compared with $5.5 \mathrm{~nm}$ for females.

\section{Mechanical Antennal Frequency Tuning}

Mechanical tuning curves were constructed from laser-diode interferometer (Lukashkin et al. 2005) measurements of the antennal flagellum vibrations, made close to the pedicel (inset Fig. 3B). We found that the mechanical frequency tuning of the antennae of male and female $T$. brevipalpis (500 and $400 \mathrm{~Hz}$, respectively; Fig. 3B) are more closely matched than previously reported $(420 \mathrm{~Hz}$ and $240 \mathrm{~Hz}$, respectively) for this species (Göpfert and Robert 2000). The reasons for the discrepancy between these results are unknown, but resonance frequency can be influenced, for example, by the size of the antennae and 
A

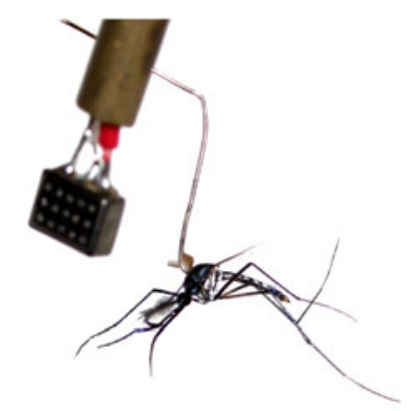

B

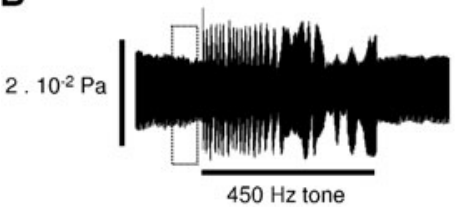

C

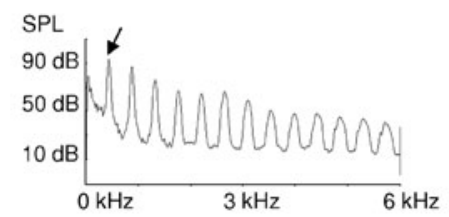

D

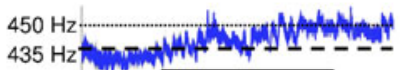

$450 \mathrm{~Hz}$ tone

E

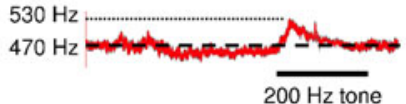

G
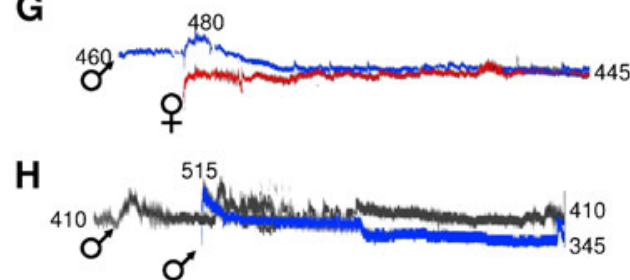

I

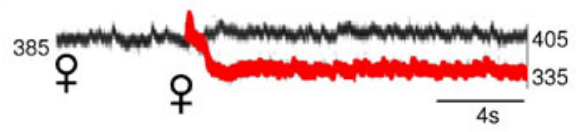

FIG. 2. Response of tethered-flying T. brevipalpis mosquitoes to pure tones and frequency convergence and divergence of flight tones by pairs of tethered T. brevipalpis. A T. brevipalpis and particle velocity microphone (largest dimension $5 \mathrm{~mm}$ ). B Oscillogram (sound level as a function of time) and $\mathbf{C}$ frequency spectrum of the flight tone of a male showing the multiple harmonics (measured during the time window indicated by the dotted rectangle in the oscillogram). Note beating between the flight tone and the first half of a $450 \mathrm{~Hz}, 55 \mathrm{~dB}$ SPL tone (duration indicated by horizontal black bar). D-F The spectrograms of mosquitoes (male blue, female red) show fundamental component of flight tones before, during and after the pure tone. Numbers alongside the spectrograms refer to flight tone frequency $(\mathrm{Hz})$ at onset of record, at peak frequency during the record, and final frequency. Dashed line indicates flight tone in the

by the stiffness of the cuticle, due to factors such as age, physiological state, and ambient temperature.

Nonetheless, it is interesting to note that our behavioral tuning curves (Fig. 3A) are more sharply tuned than our mechanical tuning curves (Fig. 3B). From our mechanical measurements, the male antenna is more effectively coupled to particle displacements than the female antenna by a factor of 2.3 , which is in agreement with previous measurements (Göpfert and Robert 2000). Thus, behaviorally, males are more sensitive than females to antennal displacement by a factor of about 3, which could be related to the observation that there are about twice as many sensillae in the JO of males than of females (Boo and Richards 1975), and, of more novel significance, behavioral thresholds in both sexes are about 10 times more sensitive than neural thresholds (Gibson and Russell 2006). These differences could be explained by neural processing (Stumpner and Helversen 2001; Hennig et al. 2004; Wyttenbach and Farris 2004).

\section{Frequency Matching}

To investigate the auditory interaction between two flying mosquitoes, we recorded the flight sounds of pairs of tethered mosquitoes held within acoustic range of each other $(5 \mathrm{~cm}$ apart). In the case of male-female pairs, their wing-beat frequencies converged within a $0.5 \mathrm{~s}$ (Fig. $2 \mathrm{~F}$ and $\mathrm{G}$ ). The wing-beat frequencies of the two mosquitoes often exactly coincided within the resolution of the frequency spectrum $(0.7 \mathrm{~Hz})$, as shown in Figure 2F.

When pairs of the same sex were flown together (Fig. 2H and I), the wing-beat frequencies of the two individuals diverged to give frequency separation between the two flight tones of $\sim 70 \mathrm{~Hz}$ (Gibson and Russell 2006). In free flight, the divergence of their flight tones would probably lead to spatial separation because it has been hypothesized that in cruising insects flight velocity should remain proportional to wing-beat frequency unless amplitude increases (Taylor et al. 2003). This auditory behavior of male mosquitoes is not unlike visual interactions between other male Diptera during the course of mate-chasing flights such as the visually driven flight oscillations of male hoverflies (Syritta pipiens); males repeatedly and rapidly respond to each other leading to an unstable interaction that quickly results in separation (Collett and Land 1975). The stereotyped frequency separation behavior observed in same sex pairs is also reminiscent 
A
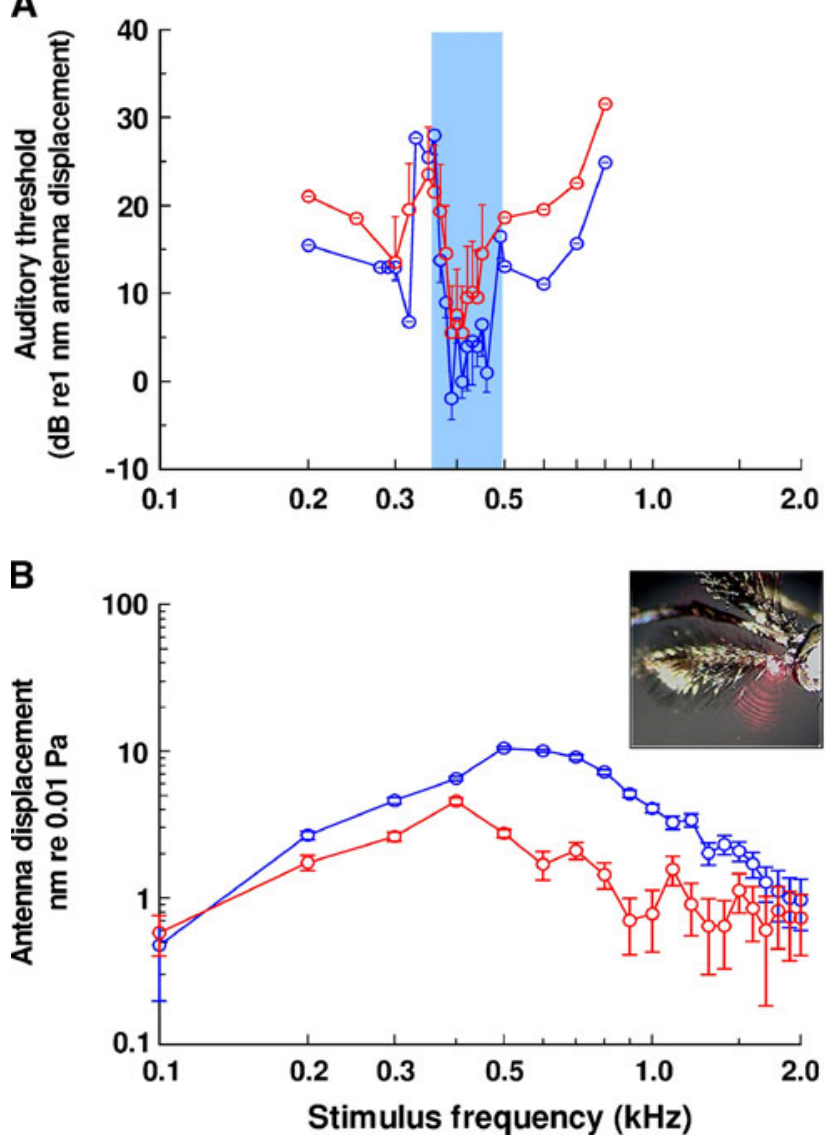

FIG. 3. Auditory frequency tuning curves of Toxorhynchites brevipalpis. A Behavioral threshold tuning curves of males (b/ue) and females (red), expressed with respect to sound-evoked displacements of antennae. Data points: mean $\pm \mathrm{SD}, n=7$ mosquitoes. The blue area indicates a frequency region where the criterion for detecting a change in wing-beat frequency was convergence of the wing-beat frequency with the stimulus tone. Tone frequencies outside this region elicited a transient increase in wing-beat frequency when the stimulus reached or exceeded detection threshold. Behavioral tuning curves were calibrated with respect to antennal displacement by relating stimulus strength to measurements taken with a laser-diode interferometer of displacement of base of the antennae by pure tones at $54 \mathrm{~dB} S \mathrm{SP}(0.01 \mathrm{~Pa})$ shown in $\mathbf{B}$. Antennal displacements of $1 \mathrm{~nm}$ were generated by a $400-500 \mathrm{~Hz}, 30 \mathrm{~dB}$ SPL tone at a distance of $3 \mathrm{~cm}$ from the speaker. B Mechanical tuning curve measured with a laser-diode interferometer (Lukashkin et al. 2005) focused on base of the antenna (inset). Antennal displacements were measured with respect to measured vibrations of the pedicil, within which the antennae is located. Data points: mean \pm SD, $n=5$ mosquitoes (from Gibson and Russell 2006, with permission of the publisher).

of the "jamming avoidance response" found in fish electrolocation and bat echolocation (Heiligenberg 1977; Ulanovsky et al. 2004).

Auditory interaction between the sexes is not uncommon amongst arthropods, although it is normally based on sequences of calls and responses produced for the sole purpose of communication (Bailey 2003). Our studies of the acoustic-motor behavior of T. brevipalpis is, however, the first demon- stration of a mating interaction in flying insects based on acoustically controlled feedback between sound input (flight tones of both mosquitoes) and motor output (changes in wing-beat frequencies) in flight muscles, which are otherwise also engaged in flight maneuvers that stabilize flight and bring the two mosquitoes closer together. It is also the first to demonstrate auditory behavior by female mosquitoes and to report a pattern of behavioral responses that separates the sexes.

\section{FREQUENCY MATCHING AT HIGHER HARMONICS; CULEX AND ANOPHELES SPECIES}

We have shown that sexual recognition in T. brevipalpis can be accomplished through wing-beat frequency matching between pairs of flying tethered mosquitoes, where males and females have similar wing-beat frequencies (Gibson and Russell 2006). Can sexual recognition be accomplished through a similar mechanism in the more common case where the fundamental wing-beat frequencies of males and females differ considerably, as is the case for medically important species of the genera Culex, Aedes, and Anopheles? Indeed it can, but the wing-beat frequencies converge not at the fundamental but on the nearest shared frequency (usually the female's third and male's second harmonic; $\sim 1,000-1,500 \mathrm{~Hz}$ ), as demonstrated by pairs of opposite sex, tethered-flying mosquitoes (Figs. 4A and B, 7A-D, Pennetier et al. 2010; Warren et al. 2009). In Figure 4B, the second harmonic of the male mosquito's wing-beat frequency converges with that of the third harmonic of the female within $1 \mathrm{~s}$ of the beginning of the record and
A

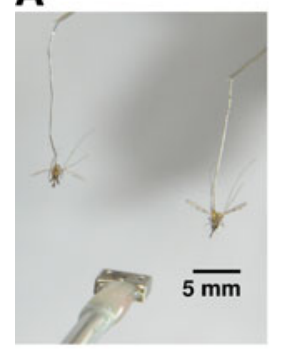

B

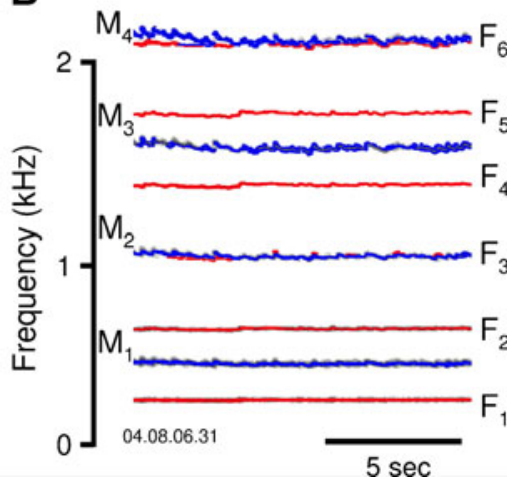

FIG. 4. Auditory interactions between tethered-flying mosquitoes. A Image on left shows arrangement of particle velocity microphone and tethered Anopheles mosquitoes during sound recordings (Pennetier et al. 2010, with permission of the publisher). B Spectrograms (reconstructed from digitized fundamental frequencies) of flight tones with harmonics of males (b/ue) and females (red) of C. pipiens mosquitoes (Warren et al. 2009, with permission of the publisher). 
they remain within a few hertz of each other for the rest of the record.

\section{Mechanical and Electrical Johnston's Organ Tuning Curves}

There is now evidence for three species of mosquito, Culex quinquefasciatus Say (Warren et al. 2009), Aedes aegypti L. (Cator et al. 2009) and A. gambiae Giles s.s. (Pennetier et al. 2010), that frequency matching of flight tones occurs at frequencies that are about three times higher than the fundamental wing-beat frequencies of females. How do these frequencies compare with the frequency bandwidth and tuning of the flagellum and the JO? Mechanical tuning curves were constructed for both male and female $C$. quinquefasciatus and A. gambiae mosquitoes. Male $A$. gambiae mosquitoes hydraulically extend and collapse the fibrillae of their antennae (Nijhout and Sheffield 1979; Fig. 5A) on a diurnal cycle linked to their swarming periods at dusk and dawn when mating occurs (Nijhout 1977; Clements 1999). These mechanical changes in the antennae alter the response characteristics of the JO (Keppler 1958). Accordingly, we obtained antennal-mechanical and JO-receptor-potential frequency tuning curves for male A. gambiae mosquitoes both during their diurnal phase of inactivity, when the fibrillae were collapsed and at dusk when they were extended. As can be seen from Figures $5 \mathrm{~B}$ and $\mathrm{C}$, the mechanical tuning curves resemble low-pass filters where the minima of the tuning curves of female A. gambiae mosquitoes are similar to those of the males, when the fibrillae of the male antennae are collapsed. With fibrillae extended (open symbols), however, the frequency of the minima of the male tuning curve more than doubles, but at the expense of low-frequency mechanical sensitivity. The sensitivity and tuning of the female flagellum had noticeable and repeatable notches of sensitivity around the first and second harmonics of the male's flight tone (arrows, Fig. 5B), similar to that reported for A. aegypti (Göpfert et al. 1999). Similar tuning curves were obtained for $C$. quinquefasciatus mosquitoes, although the flagellum of the male does not undergo diurnal changes and the minima of the tuning curves measured from female $C$. quinquefasciatus mosquitoes remain below the frequency of that obtained from the males of the same species (Warren et al. 2009). Accordingly, it can be observed from Figure $3 \mathrm{~B}$ that the frequencies at which mosquitoes frequency-match are within the frequency range of the vibrations of the flagellum (i.e., up to $\sim 2,000 \mathrm{~Hz}$ at the particle velocity expected of mosquito wings beating $2 \mathrm{~cm}$ away (Warren, unpublished). Thus, frequency matching of harmonic components is achieved within the bandwidth of the mechanical responses of the flagellum.

The minima of the receptor potential tuning curves are similar to those of the mechanical tuning curves but the low- and high-frequency slopes of receptor potential tuning curves are steeper than those of the mechanical tuning curves. Accordingly, the receptor potential tuning curves appear more narrowly tuned with band-pass characteristics (Fig. 5C). The rapid decrease in sensitivity above the minima of the receptor potential tuning curves means that, by contrast with mechanical frequency range of the flagellum, the frequencies at which the mosquitoes match their flight tones is outside the bandwidth of the JO phasic receptor potentials and thus outside the auditory range of $C$. quinquefasciatus and $A$. gambiae mosquitoes. It has been reported for A. aegypti (Cator et al. 2009) that the auditory range of the DC component of the JO receptor potential extends far above that of the phasic response and encompasses the frequency matching range. We measured DC components of the receptor potential and plotted DC frequency tuning curves (insets to Fig. 5C for $A$. gambiae and Fig. $1 \mathrm{~F}$ for C. quinquefasciatus). It is clear from our findings that DC component frequency tuning curves are bounded by the phasic receptor potential tuning and do not extend the auditory range of the JO.

Changes in the frequency tuning and sensitivity of the JO during extension of fibrillae are complex and may not entirely be due to mechanical changes in the flagellum. The electrical responses of the JO and mechanical responses of the flagellum are metabolically vulnerable when the fibrillae are extended, and can collapse within 5 min when disturbed by experimental procedures. It would be interesting to discover if there is metabolic enhancement of the sensitivity of the JO during the increased hydrostatic pressure that causes erection of the fibrillae.

We conclude that $C$. quinquefasciatus and A. gambiae match their flight tones at frequencies that are outside the bandwidth of the JO's phasic responses to acoustic stimulation but within the frequency response of the vibrations of the antennal flagellum.

\section{Difference Tone Generation by the Johnston's Organ}

So what is the mechanism by which Anopheles and Culex spp. frequency-match the harmonics of their flight tones outside the frequency range of their auditory system? The secret may lie in the properties of the Johnston's organ which shares a characteristic of the majority of hearing organs, including the cochlea, in that it is a nonlinear transducer (Kemp 1979; Kössl et al. 2008). The nonlinearity is such that 
A

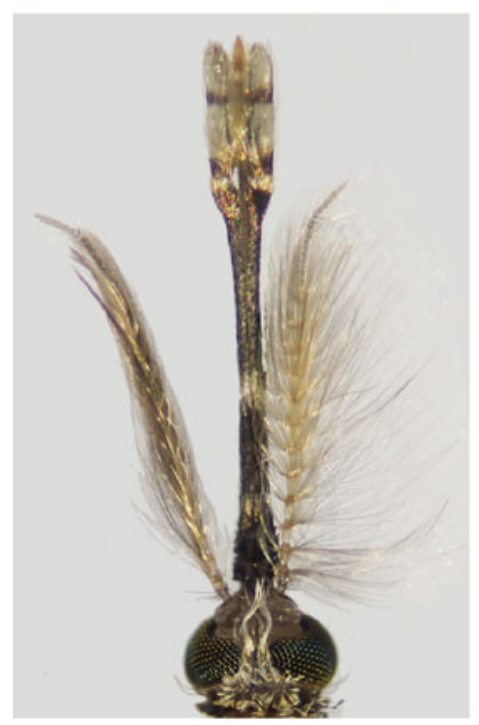

B

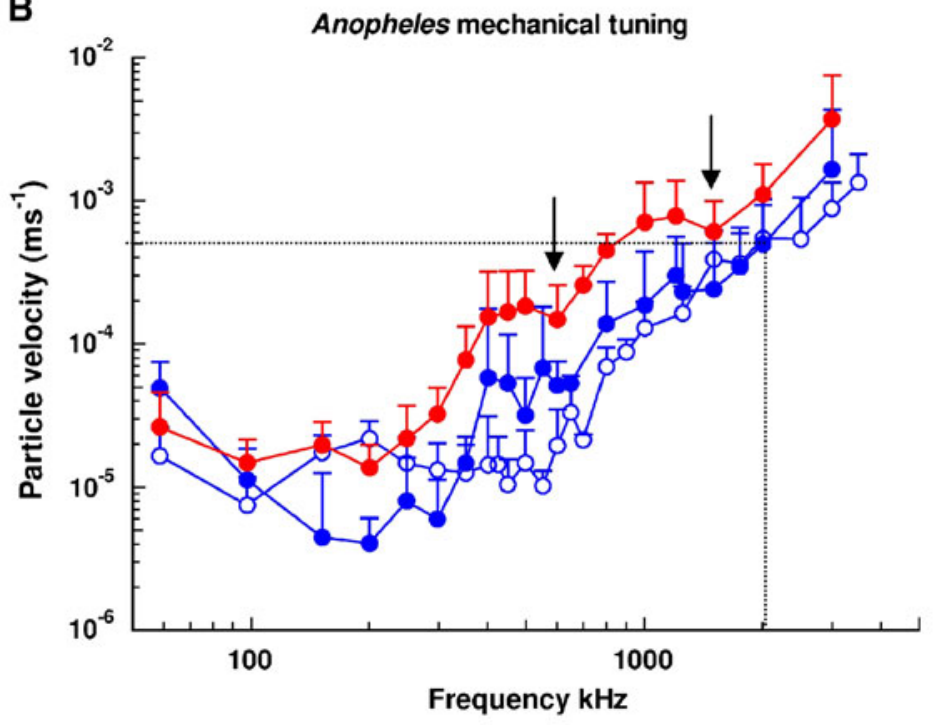

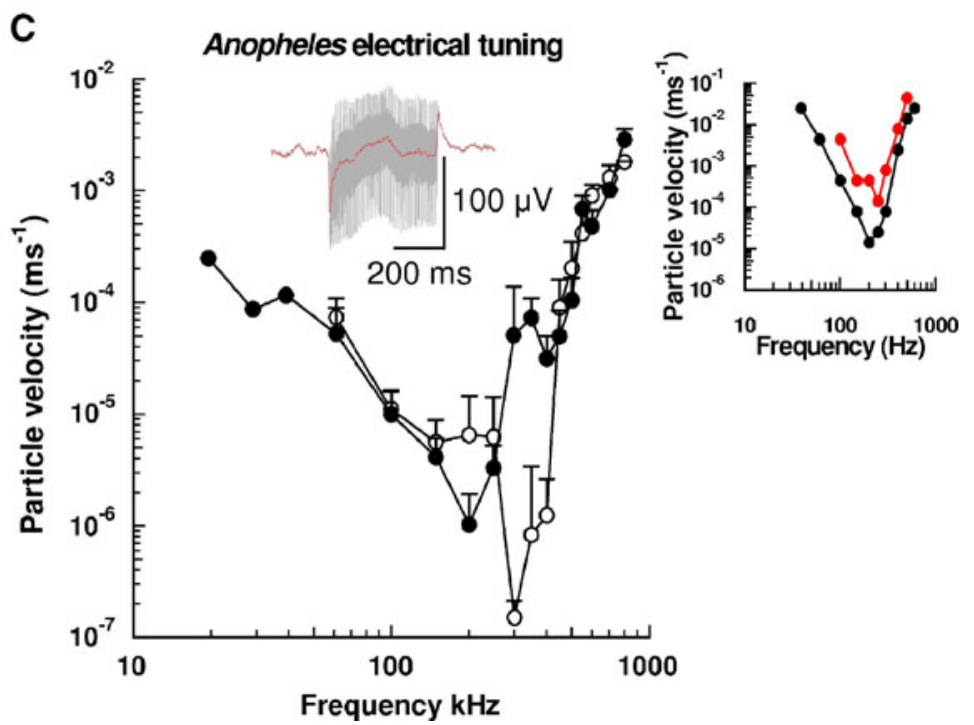

FIG. 5. Mechanical and receptor potential tuning curves from the flagellum and Johnston's organ of A. gambiae M-form mosquitoes. A Photomontage of male $A$. gambiae mosquito head, with fibrillae collapsed at left (inactive phase) and extended at right (active phase; dusk). B Mechanical threshold frequency tuning curve (mean $\pm S D$, vertical bars) measured from base of flagellum in male mosquitoes (blue symbols) with collapsed (filled symbols) and extended (open symbols) fibrillae and in female mosquitoes (red symbols). Arrows indicate sensitivity peaks at 700 and $1400 \mathrm{~Hz}$. Dotted lines indicate flight tone at the highest frequency that mosquitoes are likely to

the flagellum of the antenna, which responds to the near-field sound vibrations, appears to become stiffer with increasing stimulus level (Fig. 6A; Warren et al. 2009). This type of quadratic nonlinearity has the potential to generate difference tones (Lukashkin and Russell 1999) in the vibrations of the antenna due to the mixing of the male and female flight tones. We have shown that indeed, it is the case that the antenna produces robust difference tones in response to encounter and to which antennae can respond. C Main panel: compound phasic (2f) receptor potential frequency tuning curves (mean $\pm \mathrm{SD}$, vertical bars) measured from JO of male mosquito with collapsed (filled circles) and extended (open circles) fibrillae. Inset receptor potential (gray) with direct current (DC) component (red line) from a male with collapsed fibrillae in response to a $300 \mathrm{~Hz}$ tone, particle velocity $0.0011 \mathrm{~ms}^{-1}$. Right receptor potential tuning curves derived from the $2 \mathrm{f}$ component (black) and DC component (red) of the receptor potential (from Pennetier et al. 2010, with permission of the publisher).

stimulation by two tones, providing they are both within the frequency response range of the antenna (Pennetier et al. 2010; Warren et al. 2009; Fig. 6D and F). These difference tones elicit receptor potentials (Pennetier et al. 2010; Warren et al. 2009; Fig. 6B) and neural motor activity (Warren et al. 2009; Fig. 6C), providing the frequency of the difference tones are within the frequency range of the phasic electrical responses of the JO that detect the vibra- 

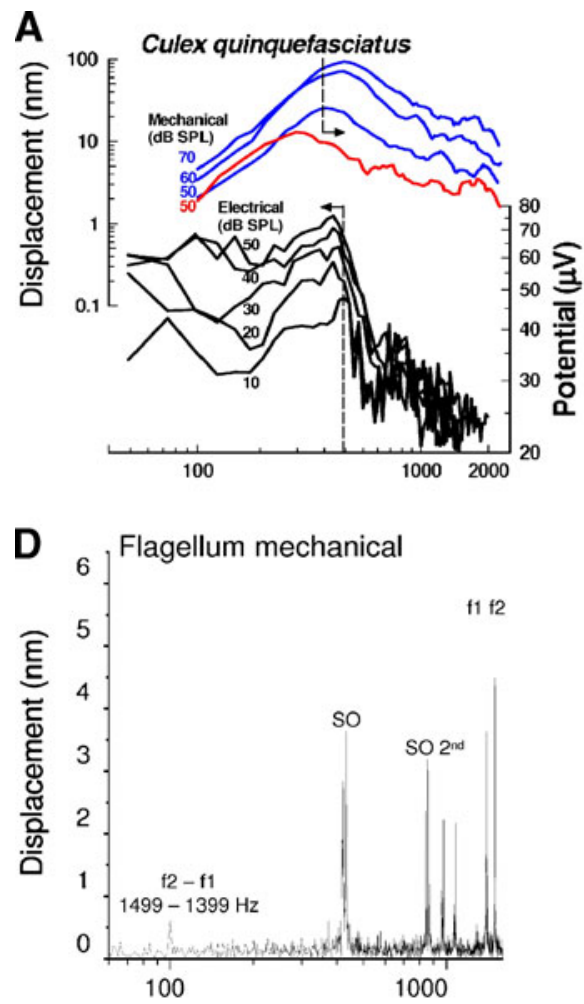

B

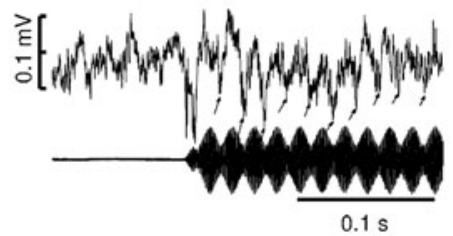

E

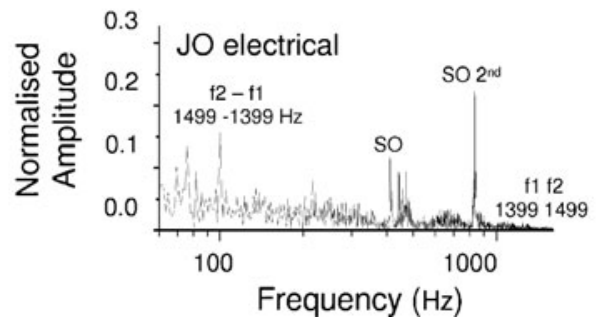

C

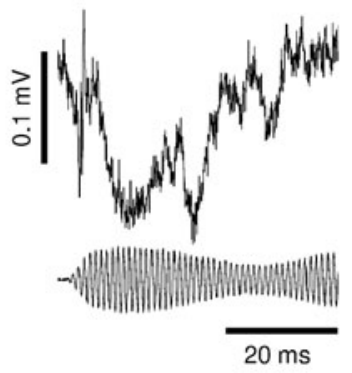

$\mathbf{F}$

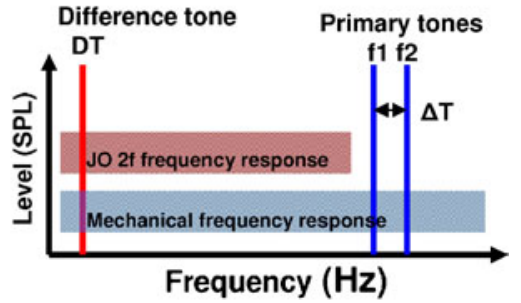

FIG. 6. evel dependence of mechanical and electrical tuning and difference tones generated in the vibrations of the flagellum and detected in the receptor potentials of the Johnston's organ. A Mechanical (male, blue; female, red) and $2 \mathrm{f}$ receptor potential (male, black) isolevel frequency tuning curves measured from the flagellum and Johnston's organs of $C$. quinquefasciatus in response to pure tones at the levels indicated. Vertical dashed lines and arrows indicate the downward frequency shift of the electrical tuning curve and upward frequency shift of the mechanical tuning curve with increasing level. B Receptor potentials (upper trace) recorded from the $\mathrm{JO}$ of a male $C$. quinquefasciatus to a combination of $1,001 \mathrm{~Hz}$ and $1,061 \mathrm{~Hz}$ tones at a particle velocity of $0.1895 \mathrm{~mm} \mathrm{~s}^{-1}$ (lower trace). C Compound neural motor response recorded at the prothoracic joint of the left foreleg in response to a pair of tones at $1,001 \mathrm{~Hz}$ and $-1,021 \mathrm{~Hz}(\mathrm{DT}=20 \mathrm{~Hz})$, both at a particle velocity of $0.1895 \mathrm{~mm} \mathrm{~s}^{-1}$. D Recordings from male $A$. gambiae of amplitude spectra of flagellum vibrations and $\mathbf{E}$ JO compound receptor potentials (lower) in response to a pair of tones at $1,399 \mathrm{~Hz}$ (f1)

tions of the antenna. Thus, responses are not elicited from the JO in response to primary tones that are delivered at the frequencies of the male's first and female's second harmonic component of their flight tones, because they are out of the frequency range of the phasic electrical responses of the JO, but phasic electrical potentials are recorded from the JO in response to the difference tone generated to these primary tones by the nonlinearity of the antenna, because these frequencies fall within the scope of the JO (Fig. 6E). Interestingly, distortion products are also generated through the interaction between flight tones and the dynein-mediated (Warren et al. 2010) spontaneous oscillations of the flagellum, although the functional significance of these nonlinear interactions has yet to be determined. and $1,499 \mathrm{~Hz}(\mathrm{f} 2)$, both at a particle velocity of $0.0011 \mathrm{~ms}^{-1}$. Responses to the primary tones ( $\mathrm{f} 1$ and $\mathrm{f} 2$ ) are seen in the mechanical but not in the electrical responses. LDifference tone ( $f 2-f 1)$ and spontaneous oscillation $(\mathrm{SO})$ responses are seen in both the mechanical and electrical spectra. The tones $\mathrm{f} 1$ and $\mathrm{f} 2$ also interact with the SOs to produce further distortion products. $\mathrm{F}$ Elements of a scheme to generate difference tones (DT) through mechanical nonlinear interaction of flight tones at the antenna flagellum of a mosquito. Flight tones interact at the level of the flagellum, which has displacement-dependent, nonlinear stiffening characteristics. Interaction of two flight tones (f1 and f2) at the level of the flagellum will occur if they are within its frequency and sensitivity range (b/ue). The frequency difference between them $(\Delta T)$ will generate a difference tone (DT) response in the receptor potential of the JO, providing the DT falls within the frequency and sensitivity range of the $\mathrm{JO}(\mathrm{red})$. $\mathrm{JO}$ responses to $\mathrm{f} 1$ and $\mathrm{f} 2$ will not be detected if they fall outside of the $\mathrm{JO}$ response range. Figures modified from Warren et al. 2009 (A, B, C, F) and Pennetier et al. 2010 (D, E) with permission of the publisher.

Frequency matching of flight tones between pairs of flying, tethered, opposite sex mosquitoes has now been demonstrated in four genera, including Toxorynchites (Gibson and Russell 2006), Culex (Warren et al. 2009), Anopheles (Pennetier et al. 2010) and Aedes (Cator et al. 2009) species. We suggest that mosquitoes detect the beat frequencies or difference tones between their respective wing-beat frequencies, and use these to maintain a relatively fixed ratio of wingbeat frequencies. The auditory information provided by the difference tone informs a mosquito not only that another mosquito is nearby, but provides exact information (an error signal) about the relative frequency ratio of their respective wing-beat frequencies. If both mosquitoes maintain a ratio that keeps them near a common frequency, then the pair are 
certain to be of opposite sex and the male has a means of tracking the position of the female, while frequency avoiding other males that may be nearby. The female may exert a degree of mate choice by changing her flight tone to see how well the male follows her, or change frequencies if she wants to "lose" him.

Mosquitoes are unusual, and perhaps unique (Gerhardt and Huber 2002; Kössl et al. 2008) in that they make use of their ability to detect low-frequency distortion products, to bring behavior that is played out at frequencies beyond the range of the phasic responses of their auditory receptors to within the scope of their hearing organ. This represents the first demonstration of an insect exploiting and responding to distortion products generated by its own auditory system for eliciting auditory behavior. There is also recent evidence that neurons in the midbrains of mammals respond to acoustic distortion products (Holmstrom et al. 2010; McAlpine 2004; Abel and Kössl 2009; Portfors et al. 2009), and that they may have a role in perceiving important characteristics of a complex tone, such as the pitch (Smoorenburg 1970; Goldstein et al. 1978). Portfors and her colleagues in their studies on the central processing and significance of ultrasonic vocalizations by mice discovered that many of the vocalization responsive neurons that they recorded in the inferior colliculus did not respond to the individual ultrasonic frequencies contained within the vocalizations, but they did respond to combinations of ultrasonic tones if the difference between the tones was within the excitatory frequency tuning curve (Portfors et al. 2009). As with the mosquito hearing organ, nonlinear interactions of frequencies, due at least in the mosquito JO to distortions in the system, may be used to mediate, or to enhance sensitivity to behaviorally important stimuli.

\section{SPECIES RECOGNITION IN A. GAMBIAE S.S.}

Given the novel nature of the physiological mechanism by which mosquitoes harmonize, what can be said about the significance of this unusual form of communication in the wider context of mosquito behavior? Does it enable mosquitoes to identify more than just the sex of the other mosquito? In the case of the malarial mosquito A. gambiae s.s., it appears that frequency matching may provide a breakthrough in the long-standing mystery as to how new species can arise out of sympatric populations of cryptic subspecies (Ritchie and Immonen 2010).

A. gambiae s.s. is a member of a species complex that consists of seven morphologically identical, yet reproductively isolated, species and several chromo- somal/molecular forms, thought to be incipient species. The complexity of malaria epidemiology and the extreme resilience with which malaria has established itself in human populations is due, in part at least, to the remarkable genetic plasticity of certain members of species complex, enabling them to adapt rapidly to an ever widening range of human-influenced habitats. This leads to rapid ecological speciation when reproductive isolation mechanisms develop (Coluzzi 1982; Powell et al. 1999; della Torre et al. 2001; 2002; Ayala and Coluzzi 2005; Costantini et al. 2009). Although reproductive isolation is essential for speciation, little is known about how it occurs in sympatric populations of incipient species (Costantini et al. 2009) .

The A. gambiae s.l. complex has become a focus of research on the evolution of species complexes to understand how populations diverge and become distinct species (Ayala and Coluzzi 2005). Within the A. gambiae complex, several degrees of reproductive isolation among its members can be observed in field populations. On one hand, formally recognized species such as A. gambiae s.s. and Anopheles arabiensis have evolved strong reproductive isolation, although a permeable species barrier still exists leading to a small degree of introgressive hybridization (Powell et al. 1999; Besansky et al. 2003). On the other hand, within A. gambiae s.s. cryptic incipient speciation has led to the recognition of several genotypic forms, which are distinguishable only on the basis of molecular markers and/or differences in chromosomal banding patterns. Two molecular forms, named "M" and "S" (della Torre et al. 2001), hybridize at different frequencies across different eco-geographical settings due to differing degrees of reproductive isolation (Tripet et al. 2001; della Torre et al. 2002; Caputo et al. 2008). These two forms are thought to have evolved through selection for populations adapted to different types of breeding site, e.g., rain-fed pools v. impounded irrigation ponds.

Although it is possible to distinguish particular molecular/chromosomal forms phenotypically by their association with one or another type of breeding water, there is no clear understanding as to how local sympatric forms became reproductively isolated in the first instance, although different patterns of mating behavior have been observed locally. In Mali, for example, unknown behavioral cues used by the two forms to identify mating swarm sites have diverged and, since they mate in segregated swarms, hybrids are rarely produced (Diabate et al. 2009); in effect, these forms are (locally) geographically separated with respect to mating behavior. However, in Burkina Faso, only $500 \mathrm{~km}$ away, $\mathrm{M}$ and $\mathrm{S}$ form mosquitoes can be found in the same swarm (della Torre et al. 2001; Tripet et al. 2001; Diabate et al. 2004; Diabate et al. 2006) and yet hybrids are notably rare, indicating the 
potential existence of a close-range barrier to interbreeding. There are no published reports of closerange mechanisms of mate recognition, and attempts to demonstrate mate recognition in the field with volatile pheromones have not been successful (JD Charlwood, personal communication, 2009). We have discovered, however, that the sexual recognition mechanism described above, also confers the capability of form-specific mate recognition (Pennetier et al. 2010).

\section{Behavioral Interactions}

We recorded the flight tones and flight tone interactions produced by tethered wild male and virgin female
$\mathrm{M}$ and $\mathrm{S}$ form mosquitoes, individually and in sameand mixed-form pairs under semi-natural conditions in Bobo Dioulasso, Burkina Faso (Fig. 4A inset). Individual male and female mosquitoes flew at mean fundamental wing-beat frequencies similar to those reported by others (Tripet et al. 2004), with males flying at significantly higher frequencies $(\sim 700 \mathrm{~Hz})$ than their conspecific females $(\sim 460 \mathrm{~Hz})$. When male-female pairs of same-form and mixed-form were flown within auditory range $(\sim 2 \mathrm{~cm})$ of each other's flight tones frequency matching occurred significantly more often in same-form pairs (14 out of 24 pairs) than in mixedform pairs (2 out of 20 pairs; Pennetier et al. 2010). Frequency matching is defined here as the mainte-
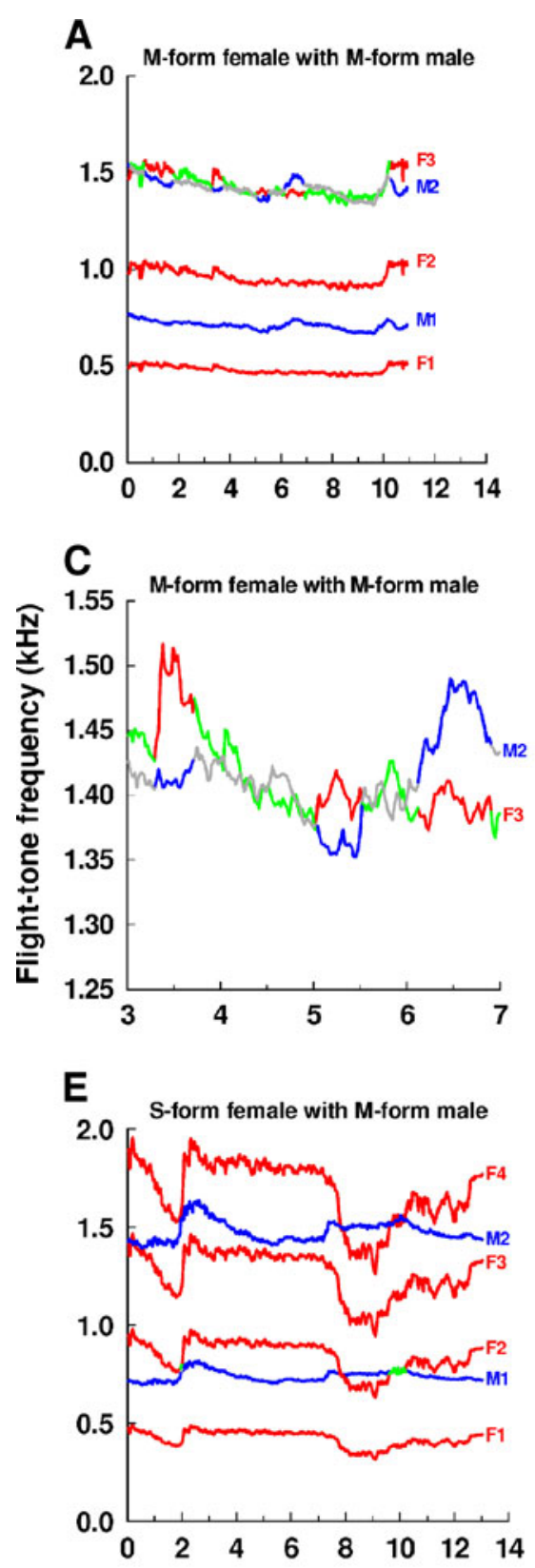
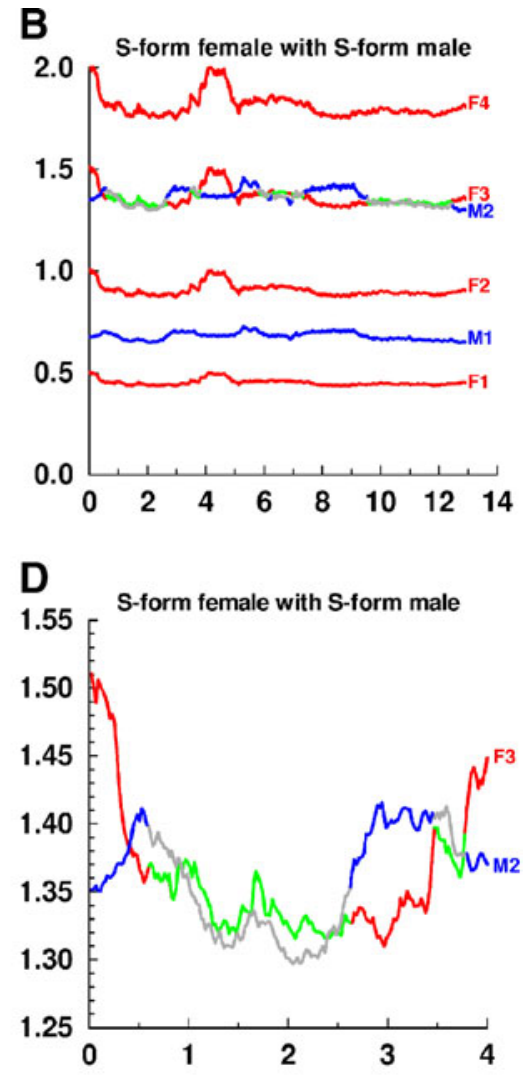

F

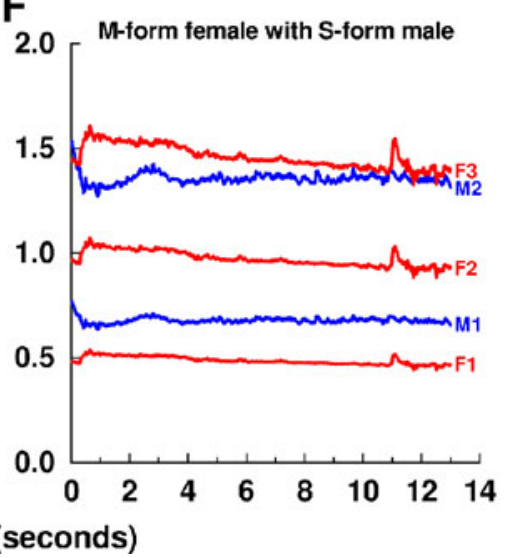

FIG. 7. Auditory interactions between tethered-flying $A$. gambiae mosquitoes. A-F Spectrograms (reconstructed from digitized fundamental frequencies) of flight tones with harmonics of males (blue) and females (red) and periods of frequency matching (gray male, green female). A and B Same-form pairs of $M$ form (A) and S-form (B) mosquitoes, showing extended frequency matching when the female's third and the male's second harmonics converge, at a ratio between their fundamental wing-beat frequencies of $3: 2$ (i.e., 1.5, a harmonicbased ratio). $\mathbf{C}$ and $\mathbf{D}$ Expanded views of $4 \mathrm{~s}$ of the spectrograms of $\mathbf{A}$ and $\mathbf{b}$, respectively, showing periods of frequency matching between the female's third and the male's second harmonics of their flight tones. $\mathbf{E}$ and $\mathbf{F}$ Mixed-form pairs of $S$ female and $M$ male $(\mathbf{E})$ and $M$ male and $S$ female $(\mathbf{F})$, showing only brief periods of frequency matching between harmonics. The ratio between their fundamental wing-beat frequencies does not stabilize at a harmonic-based value (from Pennetier et al. 2010, with permission of the publisher). 
nance of a constant ratio between the fundamental wing-beat frequencies of two mosquitoes (i.e., within $1 \%$ of ratio $=1.5$ ) for $>20 \%$ of a record and for a duration $>1 \mathrm{~s}$ (Fig. 7A and B). On the basis of our definition for frequency matching, matching pairs remained within $22 \mathrm{~Hz}$ of each other (see discussion of "difference tones" above). Figure $7 \mathrm{E}$ and $\mathrm{F}$ show examples of mixed-form pairs that fail to frequency match by these criteria.

This is the first report of a phenotypic difference in close-range mating behavior between $\mathrm{M}$ and $\mathrm{S}$ form $A$. gambiae s.s., and on the basis of these findings, we conclude that $\mathrm{M}$ and $\mathrm{S}$ form mosquitoes can discriminate between mosquitoes of the "same" and "other" form.

Previous attempts to detect potential mate recognition characteristics in the mean wing-beat frequency characteristics mosquito species may have failed because wing-beat frequencies have always been measured only in solo flying mosquitoes. Our findings demonstrate that the mean wing-beat frequency and its variance alter significantly when a mosquito detects the flight tones of another mosquito, and hence assessing wing-beat frequency in solo mosquitoes provides misleading and unreliable information about their flight tone characteristics. Also, the potential significance of the relative wing-beat frequencies of males and females at higher harmonic ratios had not yet been appreciated (Clements 1999; Tripet et al. 2004).

It is striking that this form of communication is based on no fixed "signal" and "response". The absolute mean matching frequency is variable, unique to each interaction, and can change during a matching sequence with one mosquito frequency tracking the other. For example, in Figure 7A and B the pairs of mosquitoes frequency-match at a ratio of 3:2 for a few seconds at a time (light-colored regions), reducing the variability in their respective WBFs when the ratio between them is close to 1.5 , but when they come back together after breaking apart, the mean matching frequency has generally changed. Fine timescale interactions are shown in Figure $7 \mathrm{C}$ and D to illustrate the ability of mosquitoes to respond to changes in each other's wing-beat frequency on a moment-to-moment basis with a brief $(\sim 50-60 \mathrm{~ms})$ delay. It is worth noting that both males and females actively respond to the other during these interactions, a finding that overturns the "accepted wisdom" that males only respond to the flight tones of females by chasing them, and that females are generally passive during these chases (Clements 1999).

The interactive aspect of frequency matching appears to be essential; presentation of pure tones or pre-recorded mosquito flight tones to individual tethered-flying Anopheles mosquitoes did not elicit frequency matching in either form, unlike the case of courtship song in Drosophila melanogaster, a dipteran species for which courtship song is well documented (Ritchie et al 1999; Ritchie and Immonen 2010). Analysis of factors controlling frequency matching and subsequent mating behavior must now be undertaken in free-flight experiments.

Frequency matching may have evolved due to a selected advantage of mating in free flight; frequency matching at close-range would enable the relatively small male to form a copula with the larger female in mid-flight by synchronizing with the potentially turbulent air stream generated by her wing beats (Sane 2003; Lehmann 2008). Our findings represent the first breakthrough in furthering our understanding of mosquito mating interactions since Belton's analysis of male mate localisation by sound $>35$ years ago (Belton 1974). They are also the first documentation of form-specific close-range interactions related to mating behavior since Coluzzi first put forward his theory of the evolution of reproductive isolation in diverging populations (Coluzzi 1982; Ayala and Coluzzi 2005).

\section{ACKNOWLEDGMENTS}

This research is supported by a grant from the BBSRC. BW is supported by a BBSRC studentship.

\section{REFERENCES}

Abel C, Kössl M (2009) Sensitive response to low-frequency cochlear distortion products in the auditory midbrain. J Neurophysiol 101:1560-1574

Arthur BJ, Wyttenbach RA, Harrington LC, Hoy RR (2010) Neural responses to one- and two-tone stimuli in the hearing organ of the dengue vector mosquito. J Exp Biol 213:1376-1385

Ayala FJ, Coluzzi M (2005) Chromosome speciation: humans, Drosophila, and mosquitoes. Proc Natl Acad Sci USA 102:65356542

BAILEY WJ (2003) Insect duets: underlying mechanisms and their evolution. Physiol Entomol 28:157-174

Belton P (1974) An analysis of direction finding in male mosquitoes. In: Browne LB (ed) Experimental analysis of insect behaviour. Springer, Heidelberg, pp 139-148

Belton P (1989) The structure and probable function of the internal cuticular parts of Johnston's organ in mosquitoes (Aedes aegypti). Can J Zool 67:2625-2632

Belton P (1994) Attraction of male mosquitoes to sound. J Am Mosq Control Assoc 10:297-301

Besansky NJ, Krzywinski J, Lehmann T, Simard F, Kern M, Mukabayire O, Fontenille D, Toure Y, SAgnon N (2003) Semipermeable species boundaries between Anopheles gambiae and Anopheles arabiensis: evidence from multilocus DNA sequence variation. Proc Natl Acad Sci USA 100:10818-10823

Boo KS, Richards AG (1975) Fine structure of scolopidia in Johnston's organ of female Aedes aegypti compared with that of the male. J Insect Physiol 21:1129-1139

Caputo B, Nwakanma D, Jawara M, Adiamoh M, Dia I, Konate L, Petrarca V, Della Torre A (2008) Anopheles gambiae complex 
along The Gambia river, with particular reference to the molecular forms of An. gambiae s.s. Malar J 7:182

Cator LJ, Arthur BJ, Harrington LC, Hoy RR (2009) Harmonic convergence in the love songs of the dengue vector mosquito. Science 323:1077-1079

Charlwood JD, Jones MDR (1979) Mating behaviour in the mosquito Anopheles gambiae s.l.I. Close range and contact behaviour. Physiol Entomol 4:111-120

Clements AN (1999) The biology of mosquitoes. Sensory reception and behaviour, vol 2. CABI, New York

Collett TS, LAND MF (1975) Visual control of flight behaviour in the hoverfly Syritta pipiens L. J Comp Physiol Neuroethol Sens Neural Behav Physiol 99:1-66

Coluzzi M (1982) Spatial distribution of chromosomal inversions and speciation in anopheline mosquitoes. Prog Clin Biol Res 96:143-153

Costantini C, Ayala D, Guelbeogo WM, Pombi M, Some Cy, Bassole IH, Ose K, Fotsing JM, Sagnon N, Fontenille D, Besansky NJ, SIMARD F (2009) Living at the edge: biogeographic patterns of habitat segregation conform to speciation by niche expansion in Anopheles gambiae. BMC Ecol 9:16

della Torre A, Fanello C, Akogbeto M, Dossou-yovo J, Favia G, Petrarca V, Coluzzi M (2001) Molecular evidence of incipient speciation within Anopheles gambiae s.s. in West Africa. Insect Mol Biol 10:9-18

della Torre A, Costantini C, Besansky nJ, Caccone A, Petrarca V, Powell JR, Coluzzi M (2002) Speciation within Anopheles gambiaethe glass is half full. Science 298:115-117

Diabate A, Brengues C, Baldet T, Dabire KR, Hougard JM, Akogbeto M, Kengne P, Simard F, Guillet P, Hemingway J, Chandre F (2004) The spread of the Leu-Phe kdr mutation through Anopheles gambiae complex in Burkina Faso: genetic introgression and de novo phenomena. Trop Med Int Health 9:1267-1273

Diabate A, Dabire RK, Kengne P, Brengues C, Baldet T, Ouari A, Simard F, Lehmann T (2006) Mixed swarms of the molecular M and $\mathrm{S}$ forms of Anopheles gambiae (Diptera: Culicidae) in sympatric area from Burkina Faso. J Med Entomol 43:480-483

Diabate A, Dao A, Yaro AS, Adamou A, Gonzalez R, Manoukis NC, Traore SF, Gwadz RW, Lehmann T (2009) Spatial swarm segregation and reproductive isolation between the molecular forms of Anopheles gambiae. Proc Biol Sci 276:4215-4222

FLock A (1965) Transducing mechanisms in lateral line canal organ receptors. Cold Spring Harb Symp Quant Biol 30:133-145

Gerhardt HC, Huber F (2002) Acoustic communication in insects and anurans: common problems and diverse solutions. University of Chicago Press, Chicago

Gibson G, Russell IJ (2006) Flying in tune: sexual recognition in mosquitoes. Curr Biol 16:1311-1316

Gibson G, TORR S (1999) Visual and olfactory responses of haematophagous Diptera to host stimuli. Med Vet Entomol $13: 1-22$

Goldstein JL, Gerson A, SRulovicz P, Furst M (1978) Verification of the optimal probabilistic basis of aural processing in pitch of complex tones. J Acoust Soc Am 63:486-497

GöPFERT MC, ROBERT D (2000) Nanometre-range acoustic sensitivity in male and female mosquitoes. Proc R Soc Lond B Biol Sci 267:453-457

Göpfert MC, Briegel H, Robert D (1999) Mosquito hearing: soundinduced antennal vibrations in male and female Aedes aegypti. J Exp Biol 202:2727-2738

Heiligenberg W (1977) Principles of echolocation and jamming avoidance in electric fish. Springer, Berlin

Hennig RM, Franz A, Stumpner A (2004) Processing of auditory information in insects. Microsc Res Tech 63:351-374

Holmstrom LA, Eeuwes LB, Roberts PD, Portfors CV (2010) Efficient encoding of vocalizations in the auditory midbrain. J Neurosci 30:802-819
Johnston C (1855) Auditory apparatus of the Culex mosquito. QJ Microsc Sci 3:97-102

KEMP DT (1979) Evidence of mechanical nonlinearity and frequency selective wave amplication in the cochlea. Arch Otorhinolaryngol 224:37-45

Keppler E (1958) Uber Das Richtungshoren Von Stechmucken. Z Fur Naturforsch B Chem Biochem Biophysik Biol Und Verwandten Geb 13:280-284

Kössl M, Mockel D, Weber M, Seyfarth EA (2008) Otoacoustic emissions from insect ears: evidence of active hearing? J Comp Physiol Neuroethol Sens Neural Behav Physiol 194:597-609

Land MF, Gibson G, Horwood J, Zeil J (1999) Fundamental differences in the optical structure of the eyes of nocturnal and diurnal mosquitoes. J Comp Physiol A 185:91-103

Lehmann FO (2008) When wings touch wakes: understanding locomotor force control by wake wing interference in insect wings. J Exp Biol 211:224-33

Lukashkin AN, Russell IJ (1999) Analysis of the f2-f1 and 2f1-f2 distortion components generated by the hair cell mechanoelectrical transducer: dependence on the amplitudes of the primaries and feedback gain. Acoust Soc Am 106:26612668

LuKashKin AN, Bashtanov ME, Russell IJ (2005) A self-mixing laserdiode interferometer for measuring basilar membrane vibrations without opening the cochlea. J Neurosci Meth 148: $122-129$

MCAlpine D (2004) Neural sensitivity to periodicity in the inferior colliculus: evidence for the role of cochlear distortions. J Neurophysiol 92:1295-1311

NijHout HF (1977) Control of antennal hair erection in male mosquitoes. Biol Bull 153:591-603

Nijhout HF, Sheffield HG (1979) Antennal hair erection in male mosquitoes: a new mechanical effector in insects. Science 206:595-596

PatuzZi RB, Yates GK, Johnstone BM (1989) The origin of the lowfrequency microphonic in the first cochlear turn of guinea-pig. Hear Res 39:177-188

Pennetier C, Warren B, Dabire KR, Russel IJ, Gibson G (2010) "Singing on the wing" as a mechanism for species recognition in the malarial mosquito Anopheles gambiae. Curr Biol 20: $131-136$

Portfors CV, Roberts PD, Jonson K (2009) Over-representation of species-specific vocalizations in the awake mouse inferior colliculus. Neuroscience 162:486-500

Powell JR, Petrarca V, della Torre A, Caccone A, Coluzzi M (1999) Population structure, speciation, and introgression in the Anopheles gambiae complex. Parassitologia 41:101-113

Ritchie MG, Immonen E (2010) Speciation: mosquitoes singing in harmony. Curr Biol 20:R58-60

Ritchie MG, Halsey EJ, Gleason JM (1999) Drosophila song as a species-specific mating signal and the behavioural importance of Kyriacou \& Hall cycles in D. melanogaster song. Anim Behav 58:649-657

SANE SP (2003) The aerodynamics of insect flight. J Exp Biol 206:4191-4208

Smoorenburg GF (1970) Pitch perception of two-frequency stimuli. J Acoust Soc Am 48:924-42

Stumpner A, Helversen D (2001) Evolution and function of auditory systems in insects. Naturwissenschaften 88:159-170

Taylor GK, Nudds RL, Thomas AL (2003) Flying and swimming animals cruise at a Strouhal number tuned for high power efficiency. Nature 425:707-711

Tischner H (1953) Uber Den Gehorsinn Von Stechmucken. Acustica 3:335-343

Tripet F, Toure YT, Taylor CE, Norris DE, Dolo G, Lanzaro GC (2001) DNA analysis of transferred sperm reveals significant 
levels of gene flow between molecular forms of Anopheles gambiae. Mol Ecol 10:1725-1732

Tripet F, Dolo G, Traore S, Lanzaro GC (2004) The "wingbeat hypothesis" of reproductive isolation between members of the Anopheles gambiae complex (Diptera: Culicidae) does not fly. J Med Entomol 41:375-384

Ulanovisk N, Fenton MB, Tsoar A, Korine C (2004) Dynamics of jamming avoidance in echolocating bats. Proc Biol Sci 271:1467-75

Warren B, Gibson G, Russell IJ (2009) Sex recognition through midflight mating duets in Culex mosquitoes is mediated by acoustic distortion. Curr Biol 19:485-491
Warren B, Lukashkin AN, Russell IJ (2010) The dynein-tubulin motor powers active oscillations and amplification in the hearing organ of the mosquito. Proc R Soc Lond B Biol Sci 277:17611769

Wishart G, Sickle GR, RioRdan DF (1962) Orientation of males of Aedes aegypti (Diptera: Culicidae) to sound. Can Entomol 94:613-626

World Health Organization (2002). World Health Report (2002) Reducing risks, promoting healthy life. World Health Organization, Geneva

Wyttenbach RA, Farkis HE (2004) Psychophysics in insect hearing. Microsc Res Tech 63:375-87 